\title{
Remote Biometric Authentication System using Android Phone
}

\author{
Siddhi S. Narvekar \\ Pillai HOC College of Engineering \\ \& Technology \\ Mumbai University
}

\author{
Vrushali D. Patil \\ Pillai HOC College of Engineering \\ \& Technology \\ Mumbai University
}

\author{
Swapnil Waghmare \\ Pillai HOC College of Engineering \\ \& Technology \\ Mumbai University
}

\begin{abstract}
A traditional attendance system requires a cumbersome and time consuming process requiring unnecessary paper work and higher maintenance efforts. The problem with this approach is that it requires lots of paper which are the part of our non-renewable natural resources. We are in the age, where we have to think about sustainable development. Managing the attendance using mobile phone's fingerprint scanner will provide an alternative way in this direction.

The project emphasize on the development of a standalone system that can track the attendance of the employee with the help of Wi-Fi Communication and fingerprint scanning between the employee and the management. In this project, we offer a convenient novel attendance checking method to take advantage of Wi-Fi 802.11x technology. Our application initiates AP mode Wi-Fi service for recording attendance of employee using cell phone's fingerprint scanner and for calculating salary of the employee. This smart application will connect and report to attendance server.
\end{abstract}

\section{Keywords}

Wi-Fi, biometric system, fingerprint scanner, android phone.

\section{INTRODUCTION}

It is observed that the traditional attendance system is implemented overall every industry and company. Traditional processes are prone to proxy in attendance and are insufficient towards providing transparency. Today, we need not maintain pen and paper based attendance registers. We are providing a solution to every disadvantage and flaw present in traditional attendance system by implementing the use of biometrics to identify individuals and $\mathrm{Wi}-\mathrm{Fi}$ technology to provide connectivity to a database where the entire system data can be stored and accessed easily. The mobile application would require connecting to the database using Wi-Fi technology.

Our project is an efficient and user friendly. The application will be installed on the user's android phone with fingerprint scanner. It intends to provide an interface to the management who will require minimal details to input for marking of attendance of a particular employee. The portal for the employee will open as soon as he enters the campus; the employee's mobile with the android application installed on it will mark the attendance using his/her fingerprint if it is in the range of the Wi-Fi.

Apart from that, the application would support strong user authentication and quick transmission of data via the Wi-Fi service. Employee will login to the phone application and get connected to the server. After login, they will take attendance using mobile phone using cell phone's fingerprint scanner.
Many track attendance for calculating salary and viewing holidays, that's why this application is built. In his mobile application employee can also register his name, department, designation and with the employee id. If the employee wants to see their attendance then they can see it by the application, after entering the authorized user id and the password.

\section{BASIC CONCEPT}

Here the idea is to demonstrate a small reliable standalone system that is in contact with Android application connecting to the remote main server with an efficient wireless networking terminology. The data which is sent from employee's mobile to the access point and then stored in the database. The right for manipulating the data of the employee is with the administrator. The system is proposed to be transparent to maximum extent so that admin and the employee can view the attendance respectively in a sorted manner. The application is also intended to send the information to the view salary and view holidays in the calendar.

\section{LITERATURE SURVEY}

Along with the growing number of Smartphone users, the number of applications available on smart phones also increased. But there has been no application for attendance system on a Smartphone that is easy to use and integrated with the management attendance system tool controlled by the personnel department. On the other hand, there are many disadvantage in attendance systems currently available such as a long queuing in front of the attendance machine at the time come to work and after work, monitoring employees who work outside of office, the organization has to spend on the device as well as badges, and difficult to maintain and repair the devices.

Some companies also need to monitor their employee who is working outside the office or out of town. In order to calculate the employee's salary who work outside the office, the personnel and finance department need to know how many hours the employee come to work. The problem is there is no tool that can monitor working hour of employee outside the office. Most of the time the employee just feel the sheet of paper to write down name and time by their self without any control or monitor. Therefore an automatic attendance system using voice recognition and fingerprint on Smartphone would provide the new solution [2].

Using biometric technology, people can doing authentication with simply process? People no need to remind word or number when they want to verify them self digitally. One of biometric technology in demand is fingerprint. Biometric fingerprint has now been applied in security system access, 
such as is for access to the door. Even, now Smartphone technology also uses fingerprint authentication system for unlocking the device. It's allows people to unlocking their Smartphone only by scanning their fingerprint into their Smartphone fingerprint sensor. In this paper, we will explain about the integrated system between fingerprint technology and fingerprint sensor technology on smart phone that would be applied in the digital signature concept. The goal of this paper is to develop a system that allows people to digitally sign document safely by simply scanning their fingerprint into their smart phone's fingerprint sensor [3].

As attendance is a major parameter through which the performance of a student or an employee can be judged, it is of utmost importance that the institution or company should monitor it. But, the traditional method of taking attendance is a time taking process; moreover, maintaining the records of attendance is a nerve wrecking job. This gives way to wastage of paper resources, increased human involvement and thus human errors, possible manipulation of data, etc.

Our project focuses on automating this process and ensuring minimal human involvement in the process. We have used a fingerprint sensor R305 that processes the image of the fingerprint and generates the corresponding template, which is the binary representation of the fingerprint image as captured by the fingerprint module. This template is stored and verified by the fingerprint module itself on receiving commands from the microcontroller. Hence, the process of enrollment of students and verification of the students, present, is automated. [4].

\section{EXISTING SYSTEM}

In the present system requires lot of paper work. The whole session attendance is stored in register and at the end of the session the reports are generated. We are not interested in generating report in the middle of the session or as per the requirement because it takes more time in calculation.

\subsection{Disadvantages of Present Working System:}

1. Not User Friendly

2. Difficulty in report generation

3. Manual work.

4. Lots of paperwork

5. Time consuming

6. Long queue

\section{IMPLEMENTED SYSTEM}

The implemented system overcomes the disadvantages of traditional systems; this would be a leap forward in methods of recording attendance. Doing the same work on mobile phones not only saves our resources but also enables the user to get easy and interactive access to the attendance records of employee's fingerprint. We are trying to make an application that can help the admin to take attendance of the employees through their own mobile device. The application that we are building can allow admin to take the attendance through their mobile devices, manage records, and calculate salary of the employee.

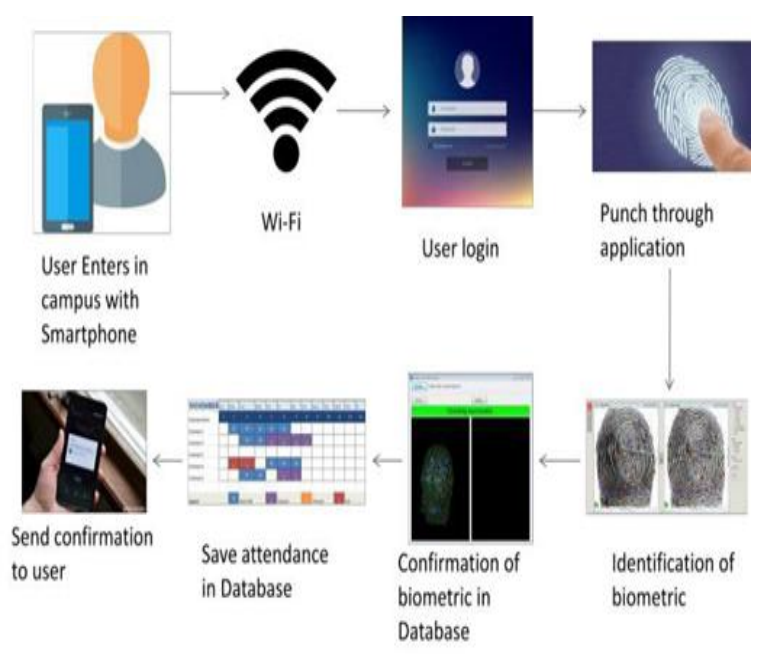

Fig.1 Architecture of Implemented Technique

\section{IMPLEMENTATION}

It is designed especially for employees to keep track of their attendance level and salary gets calculated. It has two modules.

They are-

\subsection{Admin Module}

The main purpose of the admin module is to provide security. This module is specially designed for admin, to track the attendance of the employees and maintain authenticity by using fingerprint scanner. The admin can calculate salary based on employee's attendance. The admin can add holidays in the calendar.

(a)Attendance Entry Module: The purpose of Attendance Entry Module is to enter the attendance using cell phone's fingerprint scanner.

(b)Database Module: The first function of this module is to update the attendance list from the cell phone. When the attendance list from the cell phone receives, server automatically updates its database.

(c)Adding holidays: Adding holiday is very simple as the application stores all the bank holidays and marks them on the calendar.

(d)Salary Module: This module is used to calculate salary of the employees.

\subsection{Employee Module}

(a)Add Details: Add your name, emp _id, designation and salary of the employee. This is a onetime process.

(b)Dashboard: Employee can view all pages from the dashboard. You'll be shown the dashboard every time the app runs.

(c)View attendance: Employee can view attendance daily, weekly, monthly and yearly.

(d)Salary: Employee can view salary monthly and yearly.

\section{SYSTEM WORKFLOW}

The employee will open the portal as he/she enters the premises and will mark their attendance using his/her fingerprint. As the attendance is marked automatically when the employee's mobile interacts with the access point inside the premises. The attendance is marked with the help of a 
fingerprint which is then send to the cell phone to decrypt and then to the remote administrator. The data then will be stored at the server which is controlled by the administrator, manipulation of the information of the employee such as editing the name, mobile number. The data related to the employee members is also maintained by the administrator only.
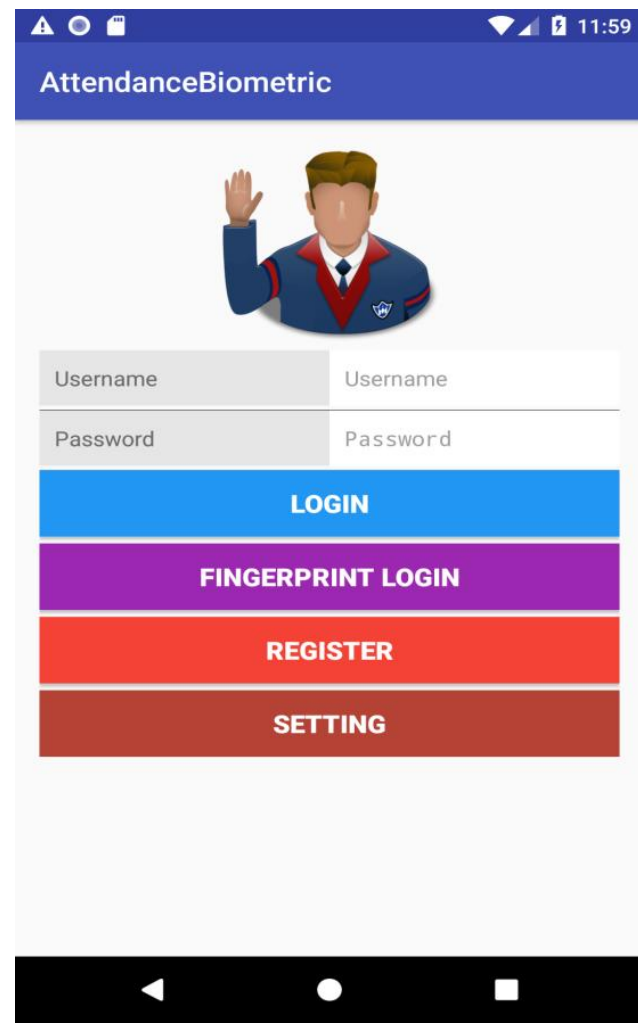

Fig. 2 System workflow of Implemented System

\section{ADVANTAGES}

The advantages of our system are as follow:

1. Easy Analysis of data.

2. Better user interface.

3. Made access to the record of attendance available $24 * 7$

4. Attendance using fingerprint.

5. Reduced dependency on natural resources for paper.

6. Easy generation of summary of attendance.

7. Provide communication between employee and admin.

8. Employees salary is generated automatically.

9. Employees can view their attendance chart.

10. Employees can view holidays marked on calendar.

\section{RESULT AND ANALYSIS \\ 9.1 Employee Panel}

$\triangle O$ O
Employee Panel

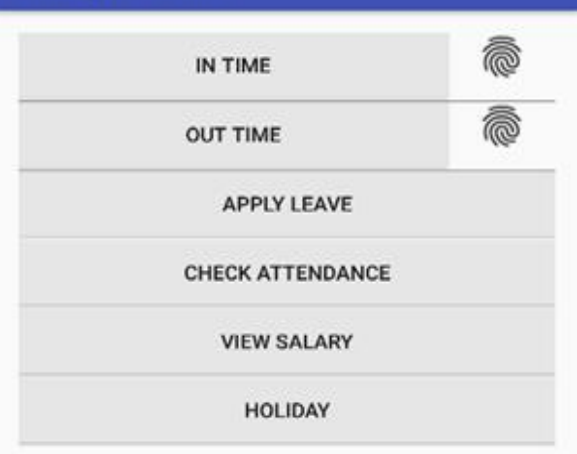

Today's attendance is marked successfully

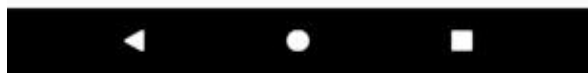

Fig.3 Attendance Marking

\begin{tabular}{l|l|}
\hline A O & \\
Leave Application & \\
\hline Leave Date & Select \\
\hline Reason & Reason \\
\hline SEND & CANCEL \\
\hline
\end{tabular}

Fig.4 Leave Application 


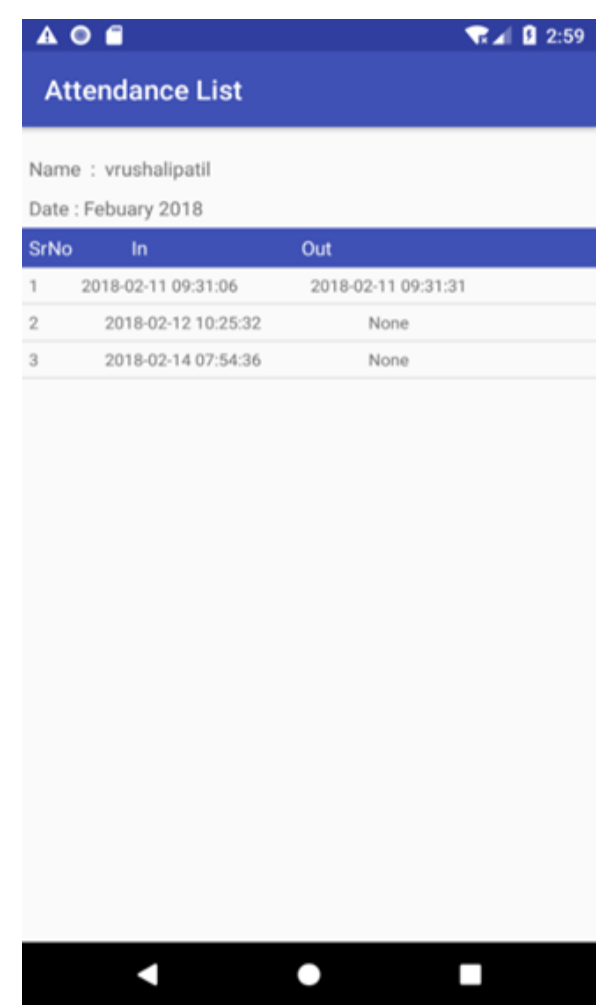

Fig.5 Attendance of Employee

$\triangle \mathrm{O} O$
Montly Salary Detail
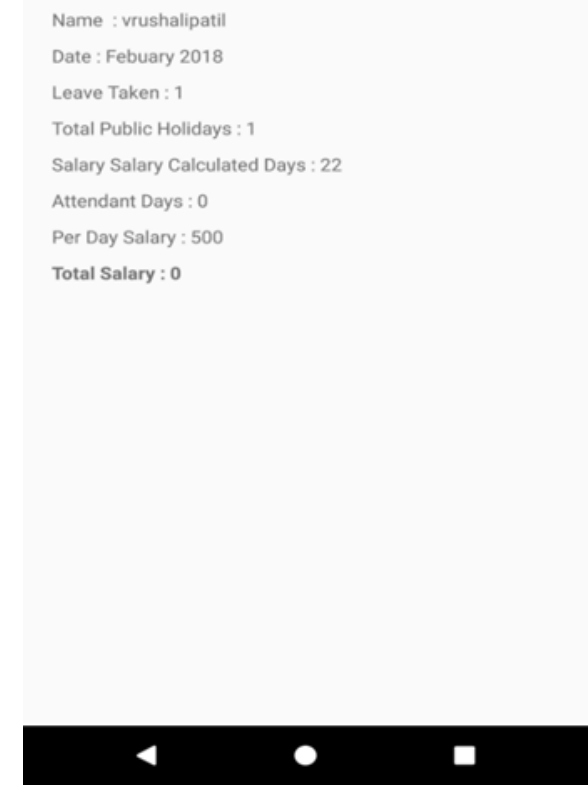

Fig.6 Salary Of Employee

\begin{tabular}{|c|c|c|c|c|c|c|}
\hline \multicolumn{7}{|c|}{$\begin{array}{l}\text { A O } \\
\text { AttendanceBiometric }\end{array}$} \\
\hline \multirow{2}{*}{$<$} & \multicolumn{5}{|c|}{ FEBRUARY 2018} & \multirow{2}{*}{$\underset{\text { SAI }}{>}$} \\
\hline & MON & TUE & WED & THU & FRI & \\
\hline 28 & 29 & 30 & 31 & 1 & 2 & 3 \\
\hline 4 & 5 & 6 & 7 & 8 & 9 & 10 \\
\hline 11 & 12 & 13 & 14 & 15 & 16 & 17 \\
\hline 18 & 19 & 20 & 21 & 22 & 23 & 24 \\
\hline 25 & 26 & 27 & 28 & 1 & 2 & 3 \\
\hline 4 & 5 & 6 & 7 & 8 & 9 & 10 \\
\hline
\end{tabular}

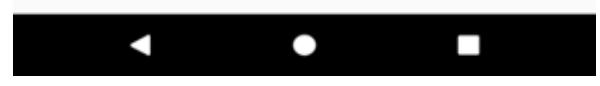

Fig.7 Holidays of Employee

\subsection{Admin Panel}

LEAVES
AttendanceBiometric
ATTENDANCE
HOLIDAYS
EMPLOYEE

\section{4}

\section{O}

Fig.8 Admin Panel 


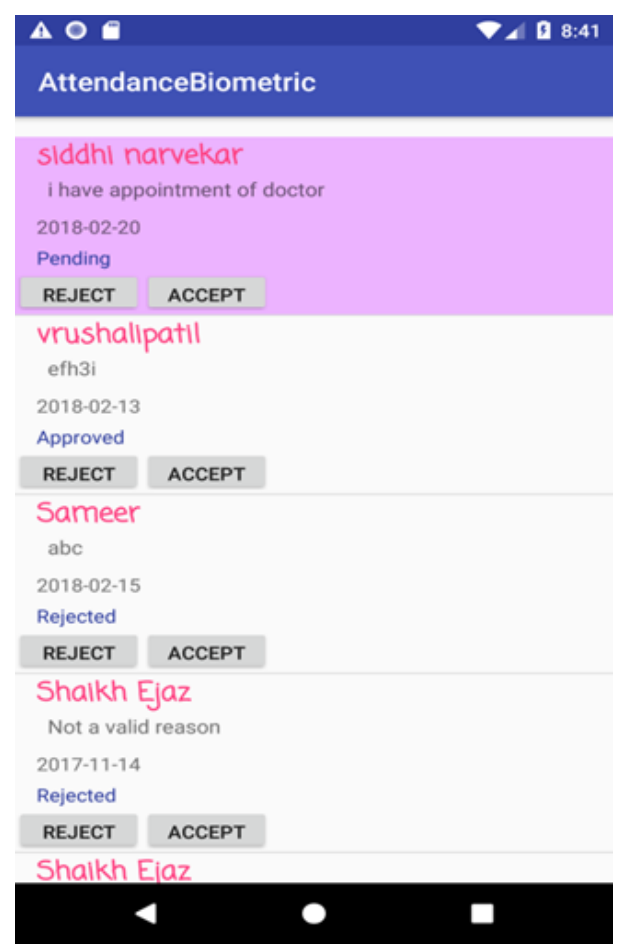

Fig.9 Leave Record

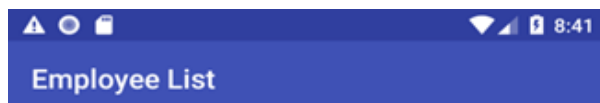

\section{s Shaikh Ejaz}

s Sameer

s siddhi narvekar

v vrushalipatil

a ashish ambavane

p payal patil

\section{$4 \quad 0 \quad$}

Fig.10 List of Employee

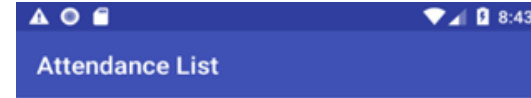

Name : siddhi narvekar

Date : Febuary 2018

\begin{tabular}{|c|c|c|}
\hline SrNo & In & Out \\
\hline 1 & 2018-02-12 05:39:-24 & $2018-02-12$ 10:34:-28 \\
\hline 2 & $2018 \cdot 02 \cdot 1407: 21: 42$ & 2018-02-14 16:12:26 \\
\hline
\end{tabular}

\section{4}

Fig.11 Attendance of a particular employee

$\mathrm{AOO}$
AttendanceBiometric

\begin{tabular}{|c|c|c|c|c|c|c|}
\hline \multicolumn{7}{|c|}{ + EVENT } \\
\hline \multirow{2}{*}{$\begin{array}{l}\text { sun } \\
\text { S }\end{array}$} & \multicolumn{5}{|c|}{ FEBRUARY 2018} & \multirow{2}{*}{$\underset{\text { SAT }}{>}$} \\
\hline & MON & TUE & WED & THU & FRI & \\
\hline 28 & 29 & 30 & 31 & 1 & 2 & 3 \\
\hline 4 & 5 & 6 & 7 & 8 & 9 & 10 \\
\hline 11 & 12 & 13 & 14 & 15 & 16 & 17 \\
\hline 18 & 19 & 20 & 21 & 22 & 23 & 24 \\
\hline 25 & 26 & 27 & 28 & 1 & 2 & 3 \\
\hline 4 & 5 & 6 & 7 & 8 & 9 & 10 \\
\hline
\end{tabular}

\section{4}

Fig.12 Holidays Marked By Admin 


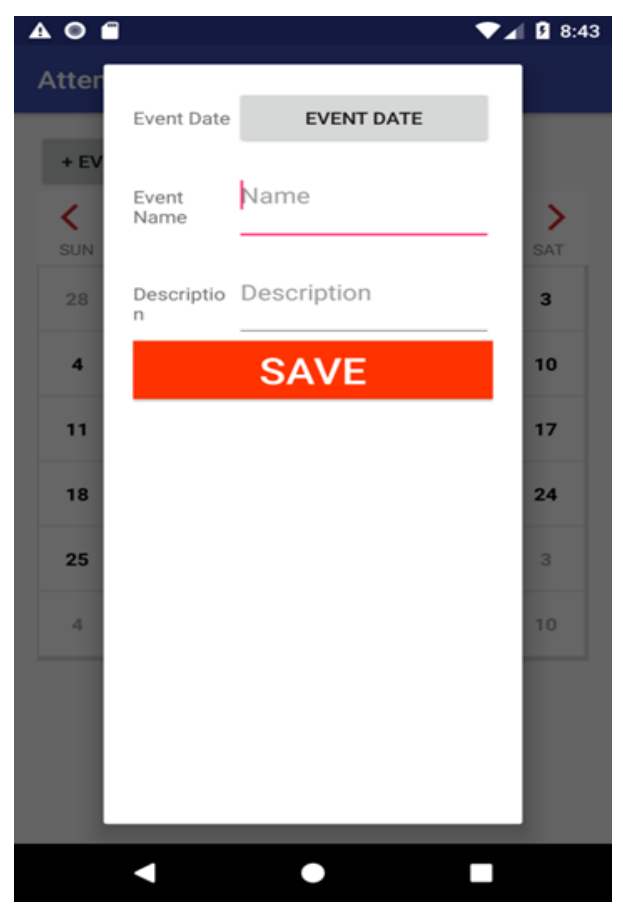

Fig.13 Event Add By Admin

\begin{tabular}{|c|l|}
\hline A O \\
\hline Employee List \\
\hline ADD EMPLOYEE \\
\hline S & $\begin{array}{l}\text { Shaikh Ejaz } \\
\text { test }\end{array}$ \\
\hline s & $\begin{array}{l}\text { Sameer } \\
\text { sam }\end{array}$ \\
\hline s & $\begin{array}{l}\text { siddhi narvekar } \\
\text { siddhi }\end{array}$ \\
\hline v & $\begin{array}{l}\text { vrushalipatil } \\
\text { vrushali }\end{array}$ \\
\hline a & $\begin{array}{l}\text { ashish ambavane } \\
\text { ashish }\end{array}$ \\
\hline p & $\begin{array}{l}\text { payal patil } \\
\text { payal }\end{array}$ \\
\hline
\end{tabular}

\section{4

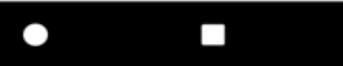

Fig.14 Employee List

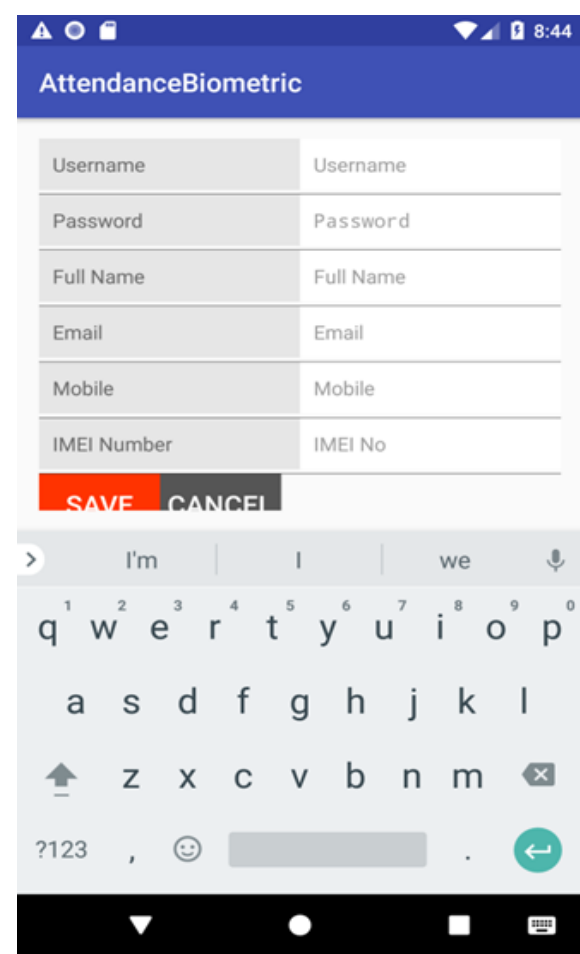

Fig.15 Add Employee

\section{CONCLUSION}

The application gives reliability, time saving and easy control. It can provide a new procedure in firms and companies for attendance. It reduces the workload by reducing the time and calculations required to update the attendance manually. It also reduces chances of proxy by using fingerprint scanner as it uniquely identifies a particular person. Admin and employee will also view the attendance and curriculum details using the application. In this paper we have discussed about the problems caused due to the use of traditional approach in taking the attendance and solutions for that through the use of mobile and provide a new approach. Automate the attendance management using mobile devices to reduce the dependencies on natural resources and also provides a way of communication between employee and admin. Integrating the employee's mobile phones with the application so that the application detects automatically Integrate it with the centralized server of the company. We will try to generate the daily report that will be submitted to the centralized server for its record. This can also use Wi-Fi technology and fingerprint scanner of the cell phone for communication between device and central server within campus.

In a future, we can add total no. of leaves of the employee, total no. of remaining leaves according to the categories such as Sick leaves, casual leaves, and leaves with payment. In a monthly salary section employee can see their salary according to their types of leaves taken.

\section{REFERENCES}

[1] Benfano Soewito, Ford Lumban Gaol, Echo Simanjuntak Fergyanto E. Gunawan,"Attendance System on Android Smartphone", International Conference on Control, Electronics, Renewable Energy and Communications (ICCEREC), 978-1-4799-8975-1/15/@2015 IEEE

[2] Benfano Soewito, Ford Lumban Gaol, Echo Simanjuntak Fergyanto E. Gunawan," Smart Mobile Attendance System Using Voice Recognition and Fingerprint on 
Smartphone”, 2016 International Seminar on Intelligent Technology and Its Application.

[3] Erika Rahmawati, Mariska Listyasari, Adam Shidqul Aziz, Sritrusta Sukaridhoto, Fardani Annisa Damastuti, Mochamad Mobed Bachtiar, Amang Sudarsono, "Digital Signature On File Using Biometric Fingerprint With Fingerprint Sensor On Smartphone", 2017 International Electronics Symposium on Engineering Technology and Applications (IES-ETA).

[4] Aditi Purohit, Kumar Gaurav, Chetan Bhati, Prof. Atul Oak," Smart Attendance", International Conference on Electronics, Communication and Aerospace Technology

ICECA 2017.

[5] Aamir Nizam Ansari, Arundhati Navada, Sanchit
Agarwal, Siddharth Patil, Balwant A. Sonkamble," Automation of Attendance System using RFID, Biometrics, GSM Modem with

.Net Framework", 978-1-61284-774-0/11/\$26.00 (O2011 IEEE.

[6] Narra Dhanalakshmi, Saketi Goutham Kumar," Aadhaar Based Biometric Attendance System Using Wireless Fingerprint Terminals", 2017 IEEE 7th International Advance Computing Conference.

[7] Sandi Fajar Rodiyansyah. 2011. Ar-sitektur

System Operating Android. (online), http://educnology .web.id/opensource/rodiyansyah/arsitektur-sistemoperasi-android, 14 January 2013. 